\title{
Determination the Effective of Grain Size on Gold Recovery by Integral of Sieve Analysis and Atomic Absorption Spectroscopy Methods
}

\author{
Amar Osman Ali Salih", *, Badawi Ahmed Zakria ${ }^{1}$, Ibrahim Mohammed Salah", \\ MohamedIdris Taha ${ }^{1}$, Bashir Algili Bashir Mohammed ${ }^{2}$ \\ ${ }^{1}$ Ministry of Higher Education and Scientific Research, Chemistry Department, Central Lab, Khartoum, Sudan \\ ${ }^{2}$ Geology Department, Faculty of Petroleum and Minerals, Alneelain University, Al Khurtum, Sudan
}

\section{Email address:}

amarcom82@hotmail.com (A. O. A. Salih)

${ }^{*}$ Corresponding author

\section{To cite this article:}

Amar Osman Ali Salih, Badawi Ahmed Zakria, Ibrahim Mohammed Salah, Mohamed Idris Taha, Bashir Algili Bashir Mohammed. Determination the Effective of Grain Size on Gold Recovery by Integral of Sieve Analysis and Atomic Absorption Spectroscopy Methods. Science Journal of Analytical Chemistry. Vol. 6, No. 2, 2018, pp. 12-20. doi: 10.11648/j.sjac.20180602.11

Received: June 3, 2018; Accepted: June 22, 2018; Published: July 31, 2018

\begin{abstract}
The sieve analysis and atomic Absorption methods were applied for 21 collected samples around Atbara region River Nile State- Sudan. Three types of grinder were used in this study they are (1) A grinder (2) B grinder and (3) mill size to given us the general trend of gold concentrate with preferable grain size in area of case study. The gold assay result for different grain size within same sample reflect direct relationship between gold concentrate and grain size which gold increasing with finer grain size. he grain size equal or less than $0.075 \mathrm{~mm}$ is the preferable size to recovery most gold from original material, and there is a difference in types of mills and efficiency, For each mill grinding time for each sample varies from the mill to another and it is reliable Depending on the test rate of the sieves in the sieves and definitely affects the reading of the concentrations of samples and therefore control the rate of raw inside is known and the percentage of milling as well as all depends on the quality control of the mining plants and reduces errors. From this study we conclude the sieve analysis isgood method to evaluate quality of various grinders.
\end{abstract}

Keywords: Sieve Analysis, Grinding, Grain Size, Quantities, Sediments, Concentrations, Flame (AAS)

\section{Introduction}

The sieve analysis, commonly known as the gradation test, is a basic essential test for all aggregate technicians. The sieve analysis determines the gradation (the distribution of aggregate particles, by size within a given sample) in order to determine compliance with design, production control requirements, and verification specifications. The gradation data may be used to calculate relationships between various aggregate or aggregate blends, to check compliance with such blends, and to predict trends during production by plotting gradation curves graphically, to name just a few uses. Used in conjunction with other tests, the sieve analysis is a very good quality control and quality acceptance tool [1]. Size is a fundamental property of sediment particles. It affects their entrainment, transport and deposition, and therefore provides important clues to the sediment provenance, transport history and depositional conditions [2]. Heavy metal pollution, owing to its permanent existence and biological enrichment, has long been an important subject in the field of international environmental science. As a result of complex physical, chemical and biological processes, a major fraction of trace metals is found to be associated with water body sediments. Sediments are multi-phase solids containing silicates, carbonates, hydroxides/oxides, sulfates and organic substances as major components [3]. The essential factors influencing the heavy metal contents in sediments include the physical and chemical properties (grain size, surface to volume ratio, heavy metal contents of the main geochemistry phase), in which grain size is a main control parameters. There is a theory that finer sediments contain more metals 
than coarser ones. The main reason is that smaller grain size particles have a larger surface-to-volume ratio [4]. However, some studies have indicated that coarser particles show similar or even higher heavy metal concentrations than finer ones and the presence of coarser particles are possibly responsible for higher metal content in the coarser size fractions [5].

\section{Literature Review}

Atomic Absorption Spectrometry (AAS) is a technique for measuring quantities of chemical elements present in environmental samples by measuring the absorbed radiation by the chemical element of interest. This is done by reading the spectra produced when the sample is excited by radiation. The atoms absorb ultraviolet or visible light and make transitions to higher energy levels. Atomic absorption methods measure the amount of energy in the form of photons of light that are absorbed by the sample, the concentration is calculated based on the Beer-Lambert law. In analytical chemistry, AAS is a technique used mostly for determining the concentration of a particular metal element within a sample. AAS can be used to analyze the concentration of over 62 different metals in a solution.

\subsection{Flame (AAS)}

Flame atomic absorption methods are referred to as direct aspiration determinations. They are normally completed as single element analyses and are relatively free of interelement spectral interferences. For some elements, the temperature or type of flame used is critical. If flame and analytical conditions are not properly used, chemical and ionization interferences can occur. Different flames can be achieved using different mixtures of gases, depending on the desired temperature and burning velocity. Some elements can only be converted to atoms at high temperatures. Even at high temperatures, if excess oxygen is present, some metals form oxides that do not redissociate into atoms. To inhibit their formation, conditions of the flame may be modified to achieve a reducing, no oxidizing flame[6].

\subsection{GrainSize}

Particle or grain size is a fundamental attribute or physical property of particulate samples or sediments and sedimentary rocks ${ }^{7}$ Much can be said from analyzing not only the size of clastic or detrital (inorganic), bioclastic (organic), or chemical particles but also from the overall size distribution, size fraction percentages, textural maturity of the sediment or sorting, surface texture attributes of a particle, and sphericity/angularity and shape of a particle[7]. Several sediment, soil, or material properties are directly influenced by the size of its particles, as well as their shape (form, roundness and surface texture or the grains) and fabric (grain-to-grain interrelation and grain orientation), such as texture and appearance, density, porosity, and permeability, The size of particles is directly dependent on the type of environmental setting, transporting agent, length and time during transport, and depositional conditions, and hence it possesses significant utility as an environmental proxy[9], as well as grinding degree on production process and for laboratory analytical technique.

\section{Materials and Methods}

\subsection{Sample Collection and Size Fractionation}

Analyzed samples were collected from Sudan _ River Nile state (Atbara region) from different depths, Transferred to the laboratory where they were dried at oven temperature $(110 \pm 5) \mathrm{Co}$, the samples were grinded by different types of grinder machine and fractionated by nest of sieves then the atomic absorption methods applied for various samples with different grain sizeto determining the relationship between grain size and gold contents.

\subsection{Method}

Preparation of standard solutions:

\subsubsection{Stock Solutions}

100 ppm purity metallic goldprepare standard gold (purity: $99.999 \%$ ) in $100 \mathrm{ml}$ volumetric flask.

\subsubsection{Standard Gold Solutions}

Prepare standard gold solutions by serial dilution of the stock solution $(100 \mathrm{ppm})$ in $100 \mathrm{ml}$ volumetric flask, preparation ofworking standard solutioninDibkfor calibration prepare emibksolution for making instrument for zero reading.

\subsubsection{Procedure}

1. Weigh $5 \mathrm{gm}$ of powdered sediment/soil samples in a graduated $500 \mathrm{ml}$ Pyrex or Borosilicate glass beaker.

2. Add $40 \mathrm{ml}$ aqua regia to the above weighed sample in a fume cupboard.

3. Leave the beaker for about 45 minutes to 60 minutes.

4. Place the beaker on a low to medium heat hot plate and boil gently for about 1 hour with frequent gentle stirring for every half an hour.

5. Reduce volume to about $4-5 \mathrm{ml}$, remove from the hot plate and cool it.

6. Transfer the entire mixture into $100 \mathrm{ml}$ volumetric flask with water and makeup the volume to the half.

7. Add $5 \mathrm{ml}$ MIBK into it and shake gently for about 50 to 60 minutes.

8. Remove the stopper full the flask to mark with water, separate the organic layer and reading in AAS.

9. Similarly process at least two numbers of CRMs/ inhouse standards in each of 20 samples.

10. In very batch of 20 samples, repeat at least one sample, following all the steps from 1 to 10 .

\subsubsection{Calibration \& Measurement}

Transfer the mixedCalibration standard solutions into the vials and arrange them in their respective positionsof the 
standards. Transfer sample solutions also into vials and arrange them frompositions, Start the calibration by clicking call Zero and if calibration graph islinear then continue analysis of the measurement of processed samples[10].

\subsection{Method of Sieve}

This test of sieve is performed to determine the percentage of different grain sizes contained within a sample. The mechanical or sieve analysis was performed to determine the distribution of the coarser, larger-sized particles.

\subsubsection{Equipment}

Balance, Set of sieves, Cleaning brush, Sieve shaker

\subsubsection{Test Procedure}

Sieve Analysis:

(1) Write down the weight of each sieve as well as the bottom pan to be used in the analysis.

(2) Record the weight of the given dry soil sample.

(3) Make sure that all the sieves are clean, and assemble them in the ascending order of sieve numbers (\#4 sieves at top and \#200 sieves at bottom). Place the pan below \#200 sieves. Carefully pour the soil sample into the top sieve and place the cap over it.

(4) Place the sieve stack in the mechanical shaker and shake for 10 minutes.

(5) Remove the stack from the shaker and carefully weigh and record the weight of each sieve with its retained soil. In addition, remember to weigh and record the weight of the bottom pan with its retained fine soil.

\section{Instrumentation}

The different grain-size fractions analyzed for gold metal contents. For determination of metal total concentrations in different grain-size fractions, sediments were digested in glass open cups with a mixture of aqua regia. The determination of metals was carried out by AAS (NOVA 350 Analytic Jena).

\section{Interferences}

The interferences caused due to non specific absorbance's can be corrected using deuterium background corrector [12].

\section{Data Analysis}

Sieve Analysis:

(1) Obtain the mass of soil retained on each sieve by subtracting the weight of the empty sieve from the mass of the sieve + retained soil, and record this mass as the weight retained on the data sheet. The sum of these retained masses should be approximately equals the initial mass of the soil sample. A loss of more than two percent is unsatisfactory.

(2) Calculate the percent retained on each sieve by dividing the weight retained on each sieve by the original sample mass.

(3) Calculate the percent passing (or percent finer) by starting with 100 percent and subtracting the percent retained on each sieve as a cumulative procedure.

Table 1. Example for Sieve Analysis Chart.

\begin{tabular}{ll}
\hline Date Tested & Tested By \\
\hline Project Name & Sample Number: \\
Visual Classification of Soil & Weight of Containergm \\
Wt. Container+Dry Soilgm & Wt. of Dry Samplegm \\
\hline
\end{tabular}

\begin{tabular}{lllllll}
\hline Sieve No(MIC) & Diameter(mm) & Soil retained(g) & $\begin{array}{l}\text { Cumulative Mass } \\
\text { Retained(g) }\end{array}$ & $\begin{array}{l}\text { Cumulative Percent } \\
\text { Retained(g) }\end{array}$ & $\begin{array}{l}\text { Percent } \\
\text { Passing(g) }\end{array}$ & $\begin{array}{l}\text { Percent } \\
\text { Passing\% }\end{array}$ \\
\hline 210 & 0.212 & - & - & - & - & - \\
150 & 0.15 & - & - & - & - & - \\
75 & 0.075 & - & - & - & - & - \\
63 & 0.063 & - & - & - & - & - \\
pan & $<0.063$ & - & - & - & - & - \\
\hline
\end{tabular}

\section{Results and Discussion}

The sieve analysis test presented a direct relationship between grain size and gold concentrate which slightly increase with finer grains, and also proved there is differences between samples which analyzed directly with plant mill size and samples after grinded in the preparation side by using AandB finer grinder, for all the assay of the mill size is less than assay after grindingdue to degree of grinding which are high on grinder A and B than plant mill size. 


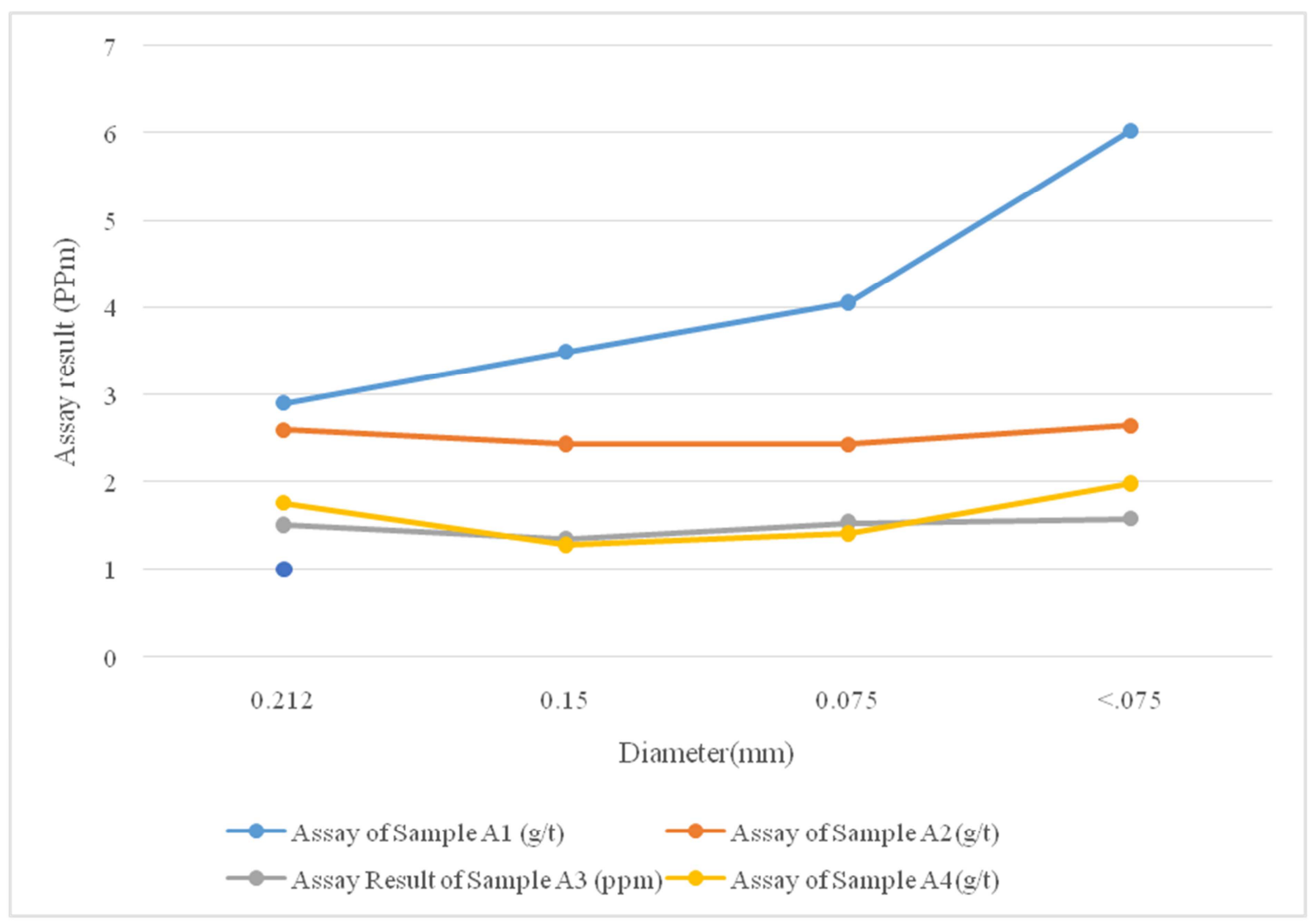

Figure 1. Chart Reflects the Increasing of Gold Concentration with Finer Grains.

The strong relationship between grain size and gold concentration appear in the above figure 1 where fineaggregates showed high gold contents when compare with gold amount of coarse aggregates for same sample.

For example: the sample A1 have gold contents decrease with grain size diameter which have more than $6 \mathrm{~g} / \mathrm{t}$ in size less than $0.075 \mathrm{~mm}$ and $3 \mathrm{~g} / \mathrm{t}$ for size $0.212 \mathrm{~mm}$.

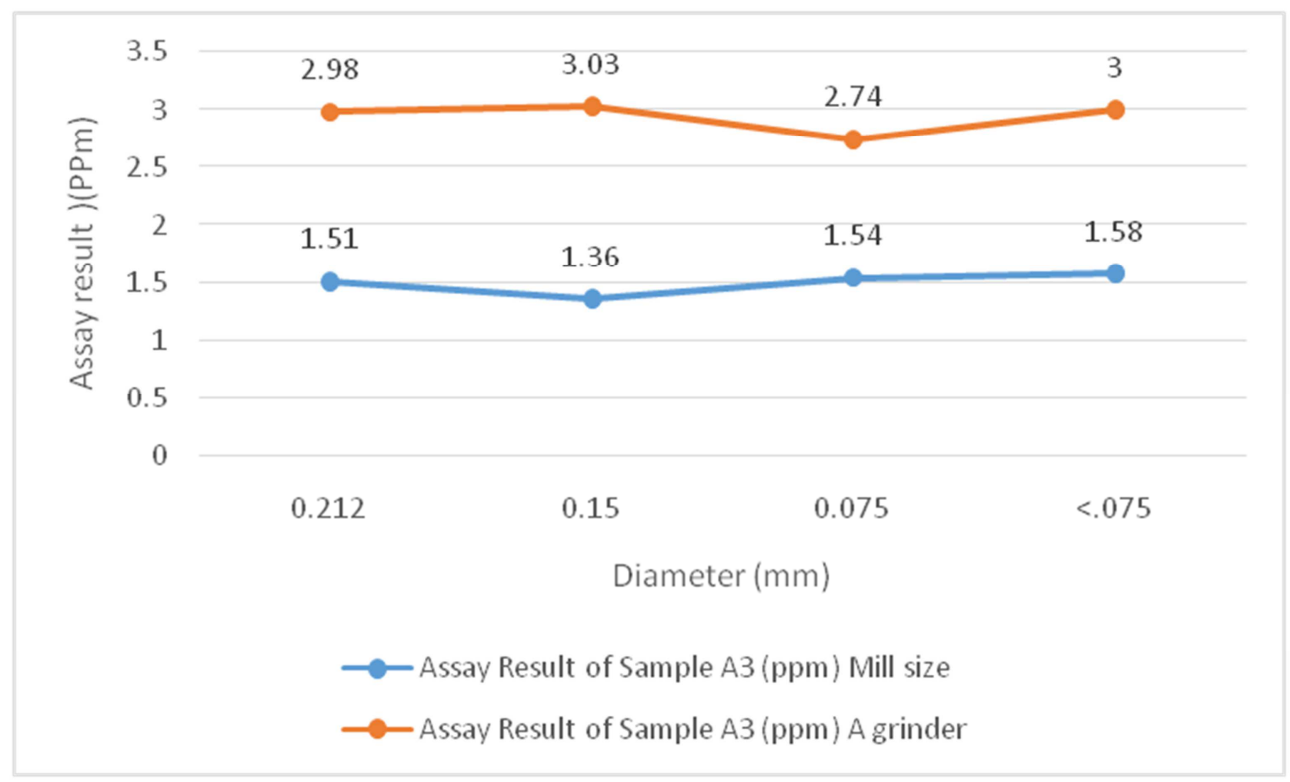

Figure 2. The Differences Between Assay Result of one Sample Through Mill and A Grinder.

All experiences applied in this paper reflected direct proportion relationship between grain size and gold amount, in the chart above the blue color represent the gold assay results Vs grain size for Sample A3 when it grinding by Plant mill where the gold content is very big with size equal to $<0.075 \mathrm{~mm}$ compared with size equal to $0.212 \mathrm{~mm}$. And the orange color represents the 
assay result of Sample A3 when grinding by A grinder and the gold increasing with fine aggregates. The pass of sample through fine mesh is very low when compare with pass percentage through fine mesh in A grinder.

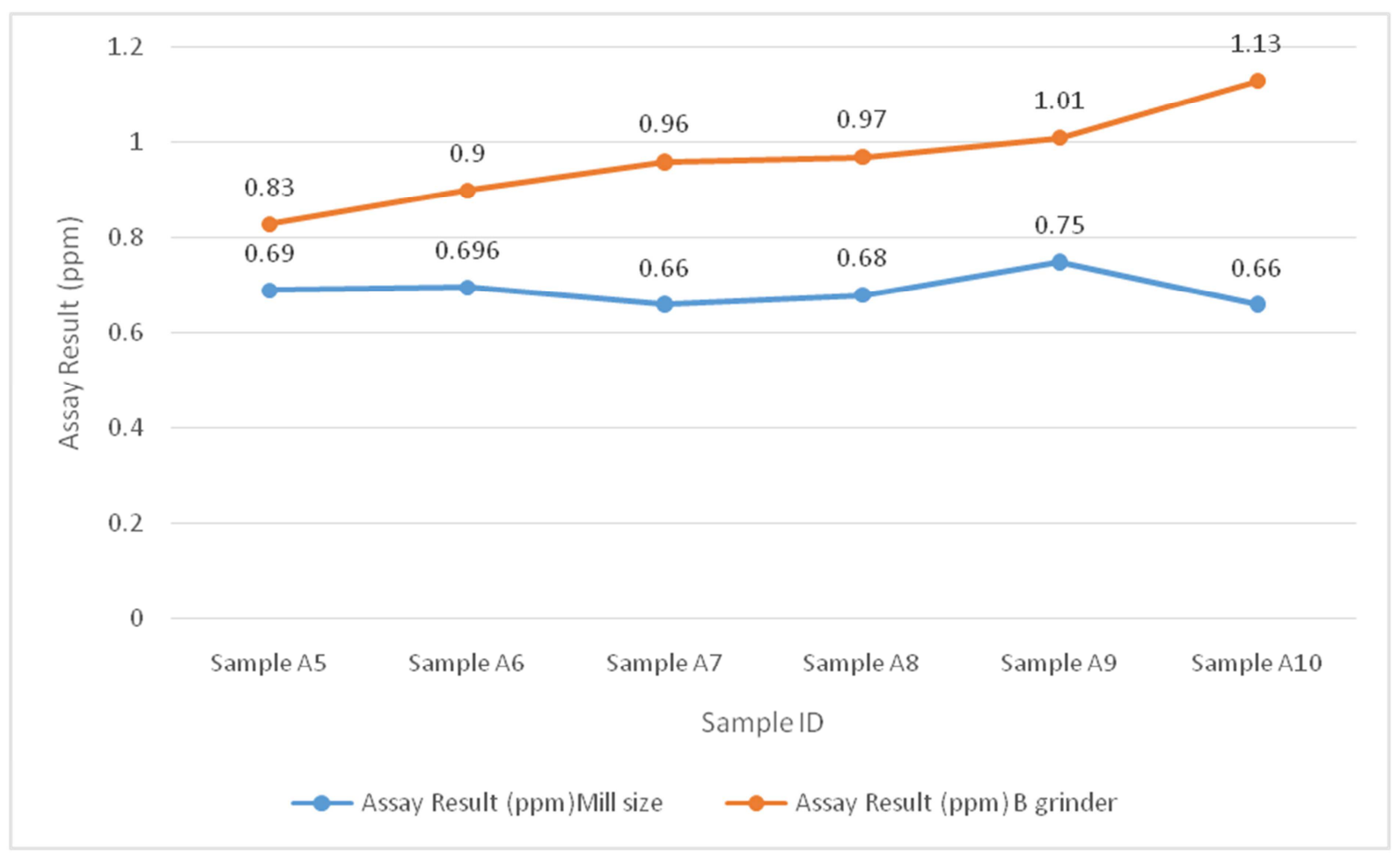

Figure 3. The Variation between Assay Results of Samples When Generated Different Grinding Size.

The chart above proved the strong relationship between grain size and concentration within sample and also the direct relation between the percentage passing of samples through mesh and gold contents where the full grinding of sample in fine grain give the accurate amount of gold in the sample. The orange and blue colors curves in the above chart reflect the assay results of gold with various grain sizes for different Samples. The effect of percentage passing diverse from plant mill compare with B grinder where the B grinder finest than mill size due to this reason we see the high gold content for samples prepared by B grinder through various mesh.

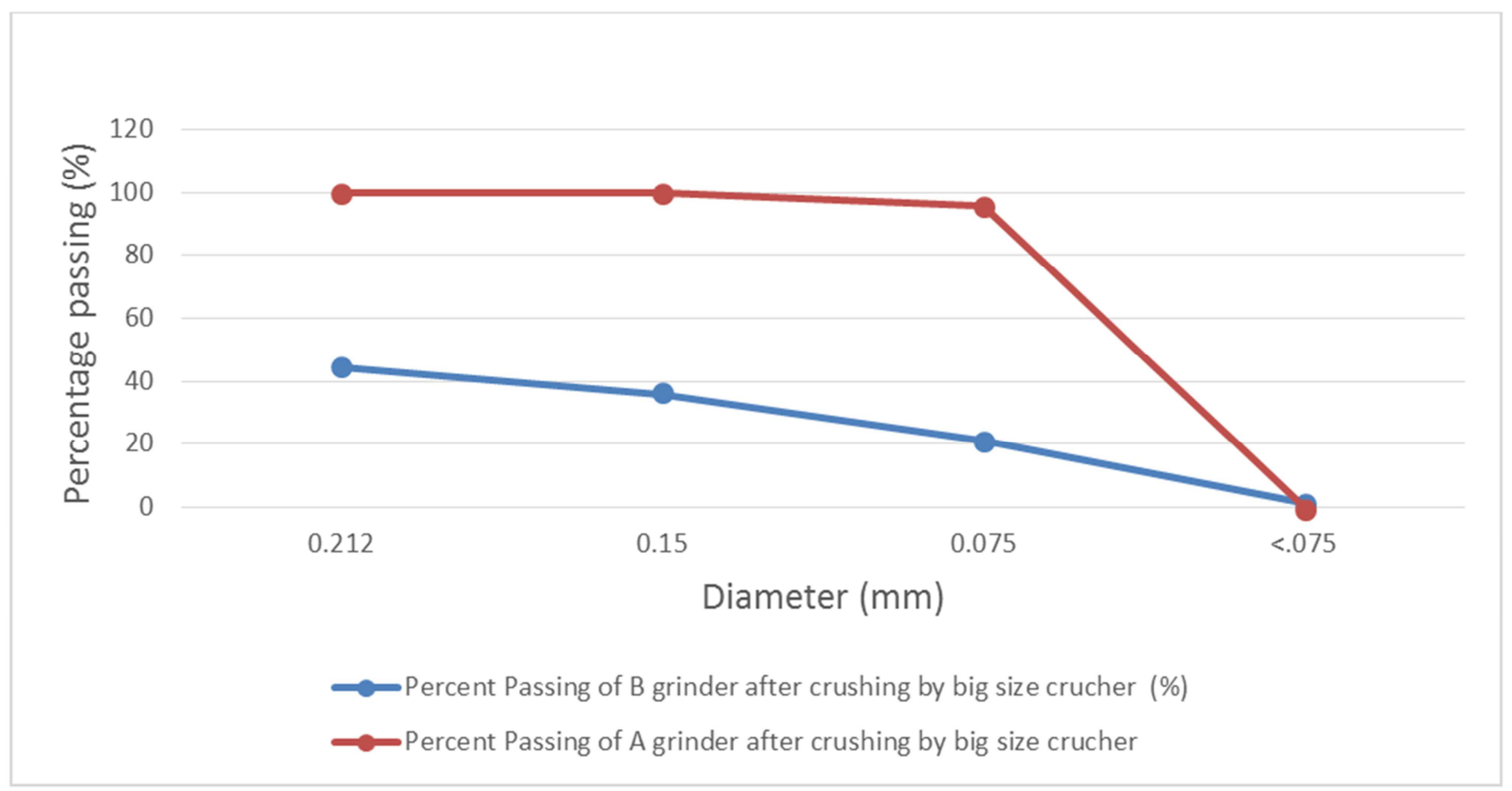

Figure 4. The Variation between B And A Grinders After Using Big Size Crusher. 
The other purpose of sieve analysis method used in this paper to estimation the degree of grinding between two different type of grinder (A and B) and proved itself as perfect method to determine the best type of grinder. Two experiments generated for this method, firstly the sample crushed by big size crusher(up to $1 \mathrm{~cm}$ grain size) then the sample put in the A grinder and B grinder simultaneously and sieve analysis generate for output samples for two grinder, at all meshes the percentage passes of $\mathrm{B}$ grinder is more than $\mathrm{A}$ grinder (Figure4), the same method above applied after used small crusher (less than $0.5 \mathrm{~cm}$ grain size) and same result concluded which the A grinder is better than B grinder in term of finest grain size (Figure5). The percentage passes for two grinder equal in the mesh less than $0.075 \mathrm{~mm}$.

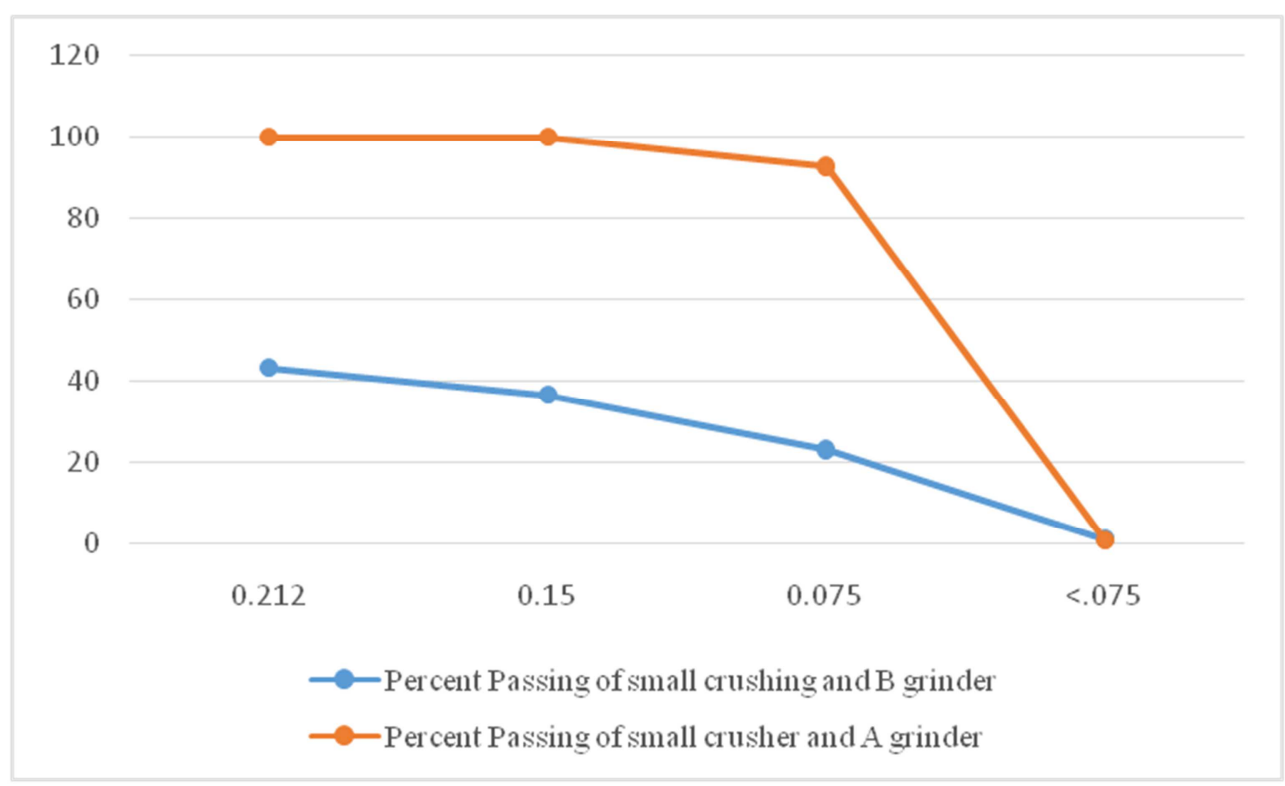

Figure 5. The Variation between B Grinder And a Grinder After Using Small Size Crusher.

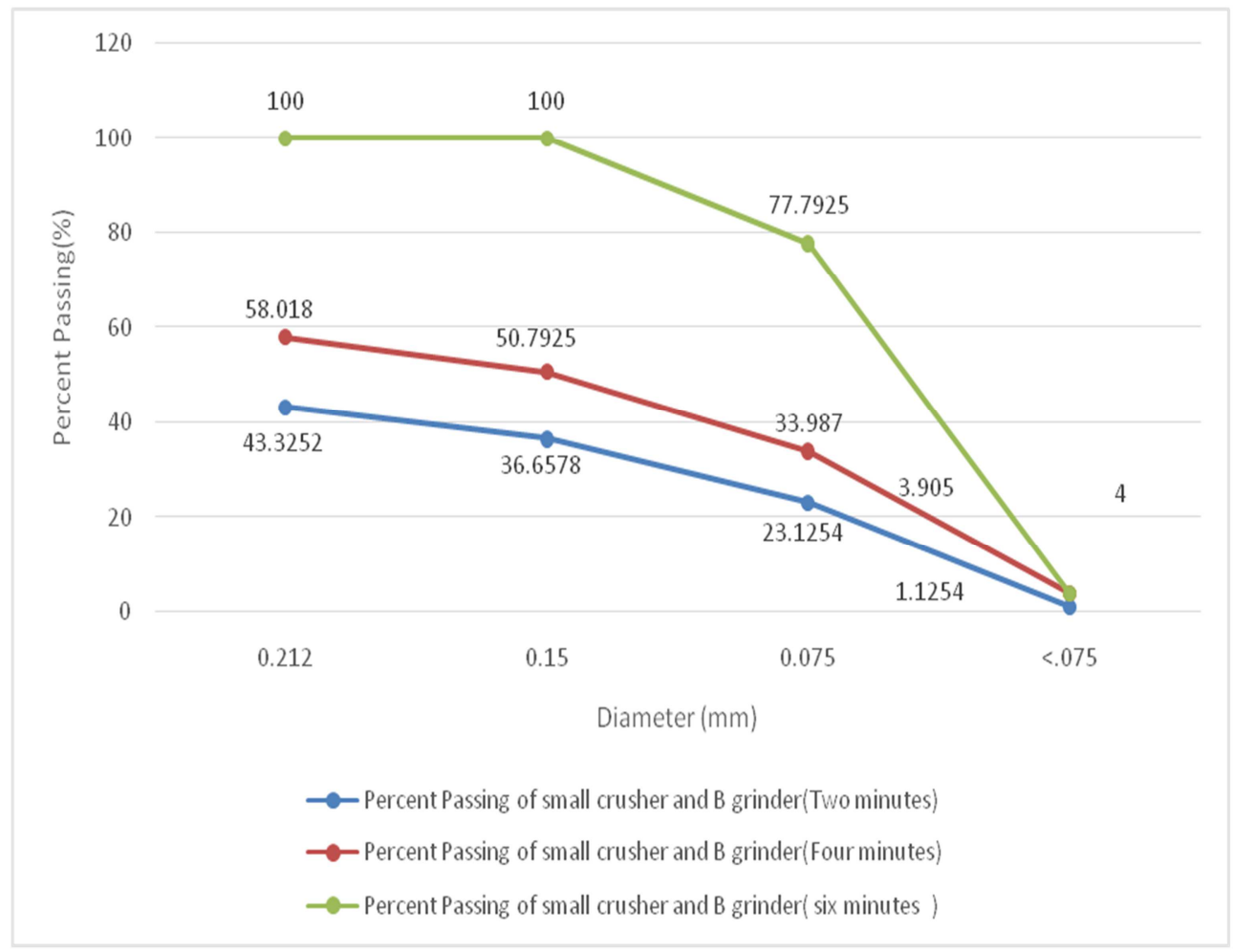

Figure 6. Chart Show the Variation ofB Grinder withTime.

To process the problem of grinder B to gets same sieve analysis results similarities to grinder A, the sample put in grinder B for different time (two, four and six minutes) and the result of sieve reflected direct proportion between grain size output and 
time effect where the fine grain increasing with time under grinding, there are perfectly matches between sieve analyses result of grinder A (one minute under grinding) when compared with sieve result of Grinder B after six minutes under grinding.

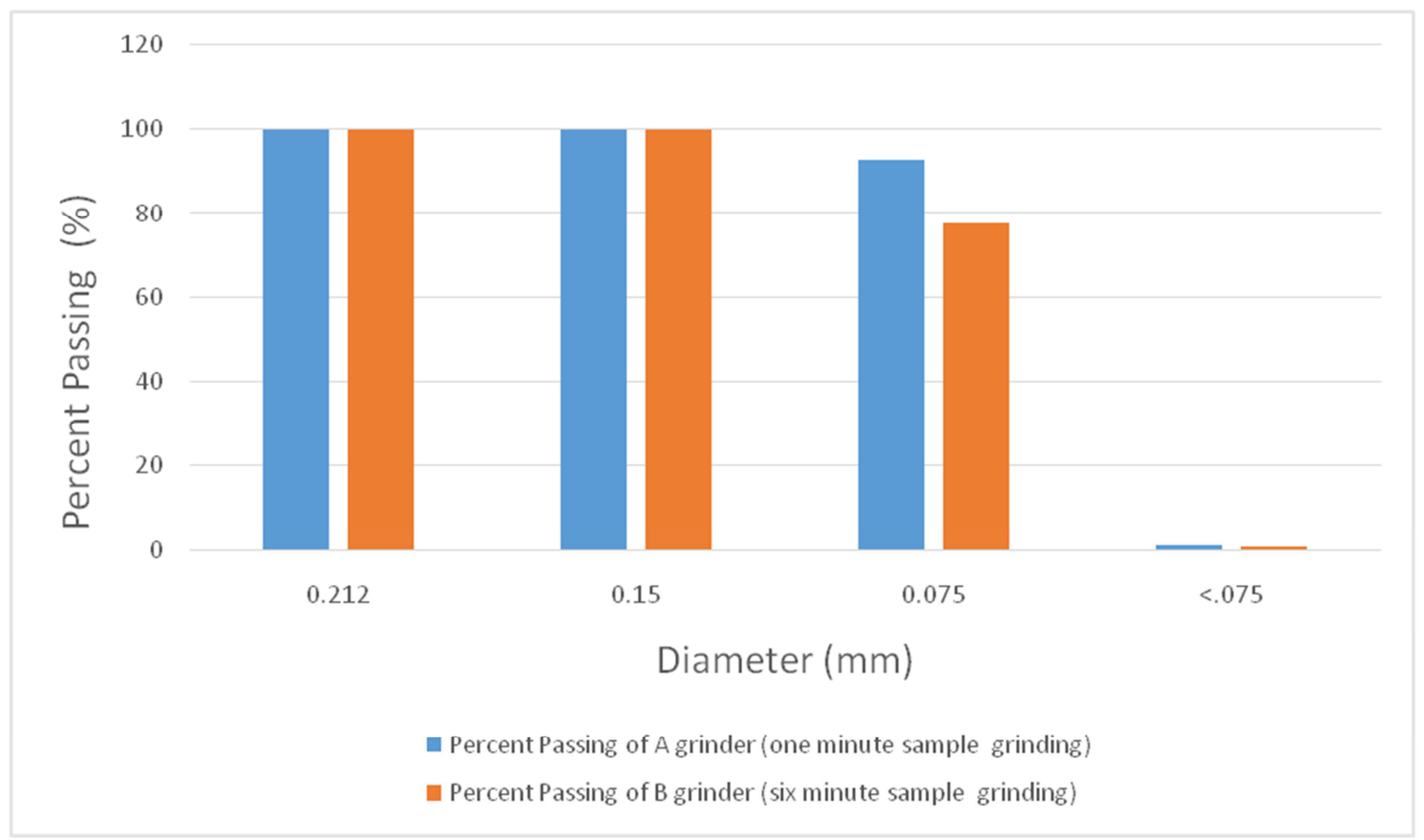

Figure 7. The Compare between B Grinding (Six Minute) and A Grinding (One Minute).

The following pie chart represent the distribution of retained grains amount in various mesh for Sample A1 after sieve analysis generated and the retained grains differs from mesh to other depend on grinding degree (Figure8)

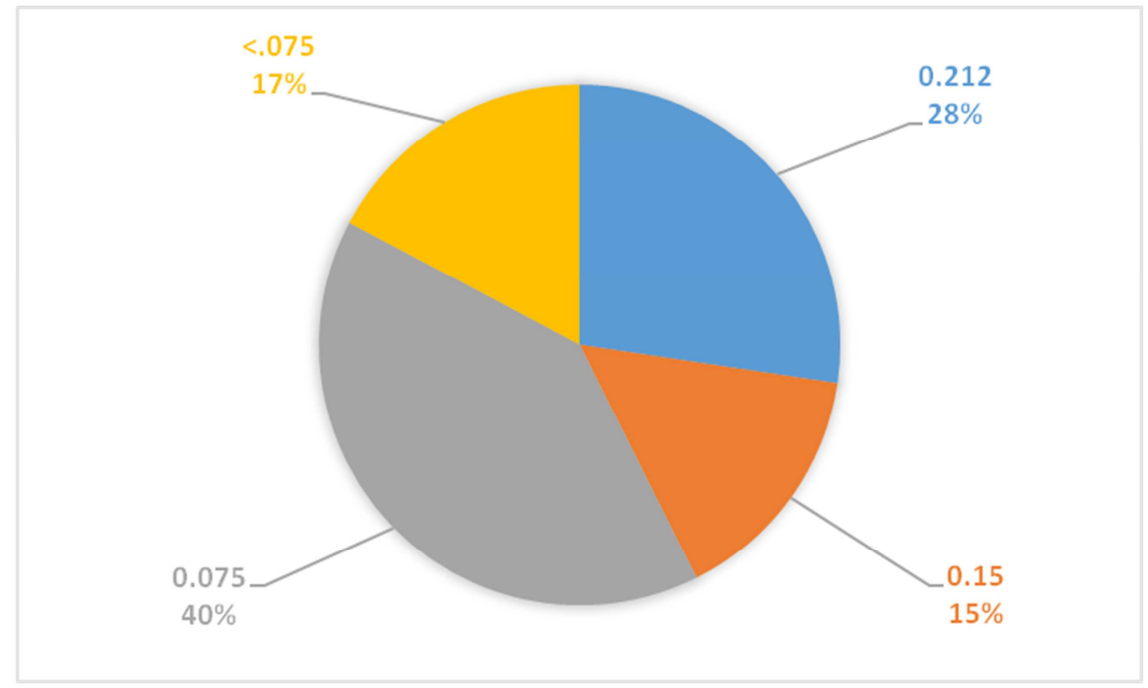

Figure 8. Percent retained at different mesh for sample A 1.

\section{The Effect of Time on Sample Analysis}

Two samples were selected to analyzed the gold concentration when samples grinding by A grinderneeded six minutes of milling time to equal the concentration of the sample or to have a degree of similarity with the other mill B which required only one minuteB grinder, The following Table and chart respectivelyshowsperfect relationship between assay results.

Table 2. Shows the relationship between the appropriate grinding time for each mill and its relation toconcentration.

\begin{tabular}{lll}
\hline Sample ID & SampleResult (Six minutes at B grinder)g/t & Sample Result (One minute at A grinder) g/t \\
\hline A 11D & 8.0225 & 7.771 \\
A 13 D & 2.656 & 2.899 \\
\hline
\end{tabular}




\section{Original vs Duplicate Assay Results}

The accuracy of the lab were checked by inserted duplicate samples within their original samples by different ID fortunately the accuracy of the lab is perfect (more than predictable), the assay results of duplicate samples semi to simultaneously their original samples (Figure 9 and Figure 10).

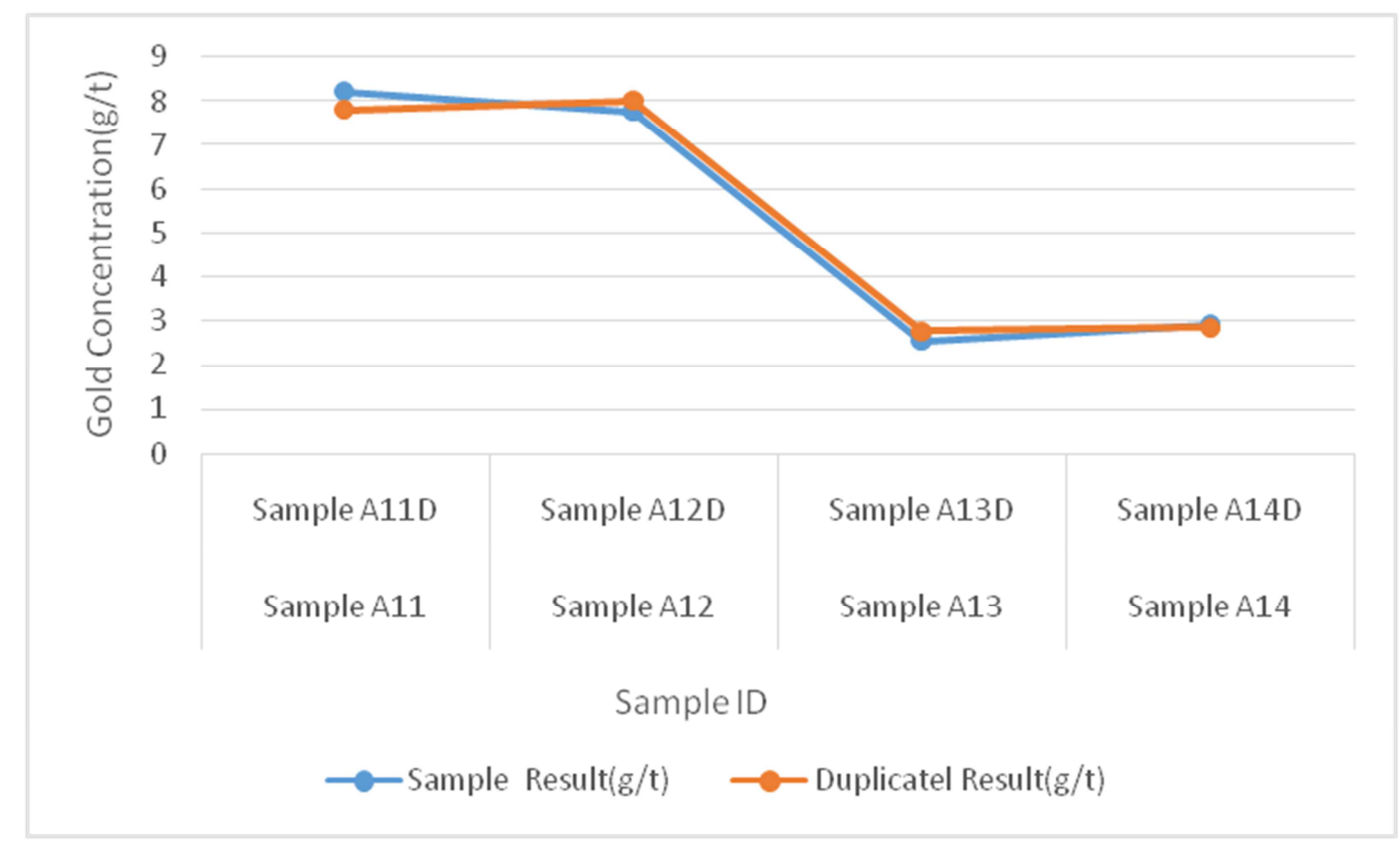

Figure 9. Orginalvs. duplicate assay results.

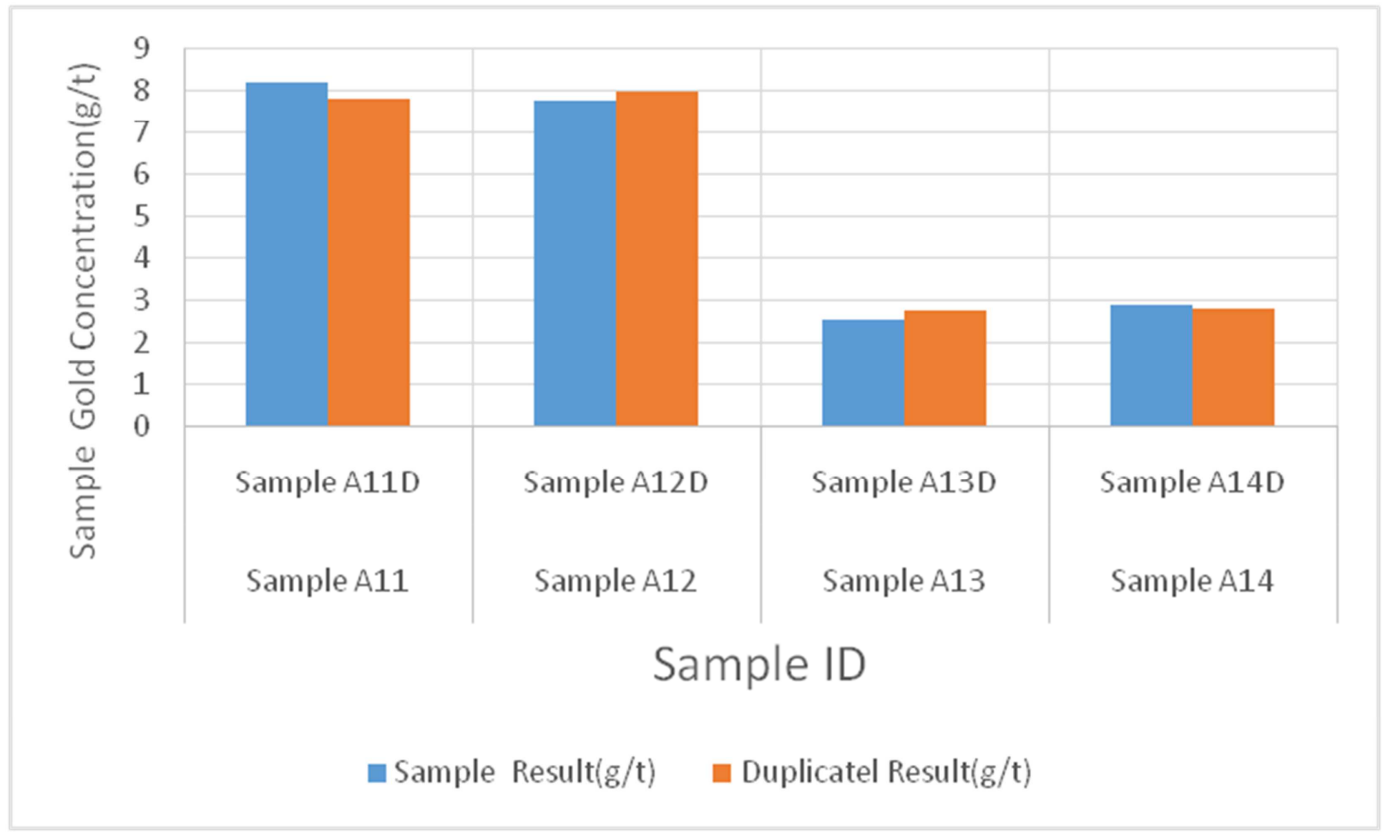

Figure 10. Column chart of original samples and duplicate.

\section{Conclusion}

Through the analyzes and experiments in this paper, all laboratory workers must verify the difference in the efficiency of the mills and determine the grinding time of the samples for each different mill established by specifying the time for each mill making them all equal in the grinding ratio, which results in correct results. The higher the efficiency of extraction, leading to quality and accuracy of work. Example (Exploration, commercial samples). Preparing samples by (B) grinder needs six minutes to equal with (A) grinder size (the preferable grain size for analyzing). To collect all gold contents from the ore material the ore must be grinding to finest degree. 


\section{References}

[1] Kenneth Pye, Simon J. Blott (2004) Particle size analysis of sediments, soilsand related particulate materials for forensic purposes using lasergranulometry. Forensic Science International: $19-27$.

[2] Ying Zhu, XiaodongZou, SupingFeng, Houquan Tang (2006) the effect ofgrain size on the $\mathrm{Cu}, \mathrm{Pb}, \mathrm{Ni}, \mathrm{Cd}$ speciation and distribution in sediments:a case study of Dongping Lake, China. Environ Geol 50: 753-759.

[3] According to AASHTO27, standard method of test for sieve analysis of fine and coarse aggregates.

[4] Martincic D, Kwokal Z, Branica M (1990) Distribution of zinc, lead, cadmium and copper between different size fractions of sediments I. The LimskiKanal (North Adriatic Sea). Sci Total Environ 95: 201-215Salomons W, Forstner U (1984) Metals in hydrocycle. Springer, BerlinHeidelberg New York, pp 349.

[5] Singh AK, Hasnain SI, Banerjee DK (1999) Grain size geochemical partitioning of heavy metals in sediments of the Damodar River-a tributary of the lower Ganga, India. Environ Geo 39(1): 90-98 Tessier A, Campbell PGC, Bisson M (1982) Particulate trace metalspeciation in stream sediments and relationships with grain size: implications for geochemical exploration. J GeochemExplor 16: 77-104.

[6] R. García and A. P. Báez Centro de Ciencias de la Atmósfera, Universidad NacionalAutónoma de México, Ciudad Universitaria, Mexico City Mexico.

[7] Folk, R. L., 1980. Petrology of Sedimentary Rocks. Austin: Hemphill Publishing. Friedman, G. M., and Sanders, J. E., 1978. Principles of Sedimentology. New York: Wiley.

[8] Krumbein, W. C., and Sloss, L. L., 1963. Stratigraphy and Sedimentation, $2^{\text {nd }}$ edition. San Francisco: W. H. Freeman.

[9] McManus, J., 1988. Grain size determination and interpretation. In Tucker, M. E. (ed.), Techniques in Sedimentology. Oxford: Blackwell Scientific, pp. 63-85.

[10] Geological survey of india, standard operating procedure, document: sop/tmsection: chemical division, issue no: 01, with some modification.

[11] According to (Qatar University Geotechnical Engineering (CVEN 230) College of Engineering Department of Civil \& Arch. Engineering).

[12] Geological survey of india, standard operating procedure, document: sop/tmsection: chemical division, issue no: 01 . 